\title{
Survived infancy but still vulnerable: spatial-temporal trends and risk factors for child mortality in the Agincourt rural sub-district, South Africa, 1992-2007
}

\author{
Benn Sartorius $^{1}$, Kathleen Kahn ${ }^{1,2,3}$, Mark A. Collinson ${ }^{1,2,3}$, Penelope Vounatsou ${ }^{4,5}$, Stephen M. \\ Tollman ${ }^{1,2,3}$ \\ ${ }^{1}$ MRC/Wits Rural Public Health and Health Transitions Research Unit (Agincourt), School of Public Health, \\ Faculty of Health Sciences, University of the Witwatersrand, Johannesburg, South Africa; ${ }^{2}$ Centre for Global \\ Health Research, Epidemiology and Global Health, University of Umeå, Umeå, Sweden; ${ }^{3}$ INDEPTH Network, \\ Accra, Ghana; ${ }^{4}$ Department of Epidemiology and Public Health, Swiss Tropical and Public Health Institute, \\ Basel, Switzerland; ${ }^{5}$ University of Basel, Basel, Switzerland
}

\begin{abstract}
Targeting of health interventions to poor children at highest risk of mortality are promising approaches for enhancing equity. Methods have emerged to accurately quantify excess risk and identify space-time disparities. This provides useful and detailed information for guiding policy. A spatio-temporal analysis was performed to identify risk factors associated with child (1-4 years) mortality in the Agincourt sub-district, South Africa, to assess temporal changes in child mortality patterns within the study site between 1992 and 2007, and to produce all-cause and cause-specific mortality maps to identify high risk areas. Demographic, maternal, paternal and fertility-related factors, household mortality experience, distance to health care facility and socio-economic status were among the examined risk factors. The analysis was carried out by fitting a Bayesian discrete time Bernoulli survival geostatistical model using Markov chain Monte Carlo simulation. Bayesian kriging was used to produce mortality risk maps. Significant temporal increase in child mortality was observed due to the HIV epidemic. A distinct spatial risk pattern was observed with higher risk areas being concentrated in poorer settlements on the eastern part of the study area, largely inhabited by former Mozambican refugees. The major risk factors for childhood mortality, following multivariate adjustment, were mother's death (especially when due to HIV and tuberculosis), greater number of children under 5 years living in the same household and winter season. This study demonstrates the use of Bayesian geostatistical models for accurately quantifying risk factors and producing maps of child mortality risk in a health and demographic surveillance system. According to the space-time analysis, the southeast and upper central regions of the site appear to have the highest mortality risk. The results inform policies to address health inequalities in the Agincourt sub-district and to improve access to health services. Targeted efforts to prevent vertical transmission of HIV in specific settings need to be undertaken as well as ensuring the survival of the mother and father in childhood.
\end{abstract}

Keywords: Bayesian inference, autoregressive, geostatistical data, child mortality, kriging, survival, Bernoulli or logistic, spatio-temporal model, health and demographic surveillance, mortality, South Africa

\section{Introduction}

Large reductions in child mortality occurred in lowincome and middle-income countries towards the end of the last century, however more than 10 million children still die every year. Most childhood deaths occur in the developing world, particularly sub-Saharan Africa (SSA), although there is considerable heterogeneity within the region with countries showing dif-

Corresponding author:

Benn Sartorius

MRC/Wits Rural Public Health and Health Transitions Research Unit (Agincourt), School of Public Health,

Faculty of Health Sciences, University of the Witwatersrand, Johannesburg, South Africa

Tel: +27 11 717-2627; Fax: +27 11 717-2084

E-mail: benn.sartorius@wits.ac.za ferential trends in levels and age patterns of childhood mortality. Childhood mortality rates have considerably declined over the past decades in much of SSA, but since the 1990s mortality rates have started to increase again in parts of the continent (Ahmad et al., 2000; WHO, 2002). This new trend has mainly been attributed to the effects of the HIV/AIDS epidemic and to the spread of chloroquine-resistant malaria (Müller et al., 1999; Adetunji, 2000; Trapé, 2001). Other prominent causes of death among children include diarrhoea, pneumonia, measles and the underlying cause of malnutrition for deaths among children younger than 5 years. Most of these conditions are either preventable or treatable with low-cost interventions (Tulloch, 1999; Black et al., 2003).

Gaps between mortality of wealthier and poorer children within most countries are unacceptably wide 
and in some areas this gap is increasing (Wagstaff, 2000). Targeting of health interventions to poorer or higher risk individuals and/or communities and ensuring universal coverage are promising approaches for promoting equity. Successful approaches include subsidised health care and health inputs, improved geographic access to health interventions in poor communities and social marketing (Victora et al., 2003). Geostatistical models allow accurately quantifying inequities in health, identifying risk factors for mortality within a population and predicting mortality at unsampled locations, and ultimately generating smoothed maps of mortality risk. Despite the increasing use of Bayesian geostatistical models in risk mapping and prediction of parasitic diseases such as malaria (Gemperli et al., 2006; Gosoniu et al., 2008; Hay et al., 2009; Riedel et al., 2010), schistosomiasis and soil-transmitted helminthiasis (Raso et al., 2005; Clements et al., 2008; Schur et al., 2011), little or no work has been done on mortality data from health and demographic surveillance sites (HDSS). Geostatistical model-based predictions of mortality at non-sampled locations can generate smoothed maps that can be used for identifying clusters of high mortality and assessing effectiveness of interventions.

Child mortality in developing countries is mainly associated with measurable socio-economic conditions such as poor living conditions (Manda, 1999). Poor children are more likely to be exposed to health risks, and have less resistance to disease because of malnutrition and other risk factors typical of poorer communities. These inequities are further compounded by reduced access to health care in the form of preventive and curative interventions. Other proximate determinants of child mortality include maternal factors (e.g. age, pace of childbearing and death of mother), nutritional factors, environmental contamination, injury and health care access and quality (Mosley and Chen 1984a, b; Hobcraft et al., 1985; Binka et al., 1995; Ronsmans, 1996; Kuate Defo, 1997). Issues of access which include accessibility (distance to facility), affordability and acceptability of available health services also heavily contribute to child mortality. Geography and ethnicity can both lead to failure to access health care, and therefore inequity in child survival. A previous study in the Agincourt HDSS, a rural South African population, showed a higher level of childhood mortality (particularly in those children aged 1-5 years) among former Mozambique refugees when compared to South African households and confirmed various other established risk factors (Hargreaves et al., 2004). Indeed, Hargreaves and col- leagues (2004) suggested that the lack of legal status, "refugee" villages being more isolated with less infrastructure, and lower wealth of many former Mozambican refugees (three times more likely than host South African households to be in the poorest quintile of the sample) may partly explain this disparity (Kahn, 2008). This should be kept in mind when assessing spatio-temporal trends in child mortality in this area. Another factor is the impact of dysfunctional health services, while communities have geographic access to adequate health services, they may fail to derive any benefit from them (Penchansky et al., 1981; Mulholland et al., 2008). There is still a need for more research in the Agincourt sub-district and other poor rural settings of sub-Saharan Africa to clarify the role of factors such as distance to nearest health facility on child morbidity and mortality as well as to identify any poorly functioning health facilities in addition to the traditional risk factors mentioned above. Given the inherent spatial (households and villages) and temporal (repeated measurements on a child each year) correlation in longitudinal data, Bayesian spatio-temporal models provide the most appropriate methodology for risk factor analysis as they take into account both sources of correlation. Standard approaches on the other hand assume independence of outcomes such as mortality and under/over estimate the magnitude and precision of the of effects of risk factors.

The objectives of this study were to assess changes in child mortality patterns within the rural Agincourt subdistrict over a 15 -year period, accurately quantify risk factors and develop all-cause and cause-specific mortality maps to identify high risk areas within the Agincourt area. This will provide guidance on how best to allocate limited resources to reduce child mortality and information on effectiveness of current health policy.

\section{Materials and methods}

\section{Study area and population}

The Agincourt HDSS was demarcated in 1992 and comprises a mix of temporary migrant workers, former Mozambican refugees and a more stable permanent population (Tollman et al., 1999) (Fig. 1). It covers an area of $\sim 400 \mathrm{~km}^{2}$ and contains 21 villages with approximately 11,700 households and 70,000 people. A full geographical information system (GIS) exists for all households within the site and is updated annually. The study population consisted of all children (aged 14 years) who were either resident, born, or in-migrated into the site between 1992 and 2007. 

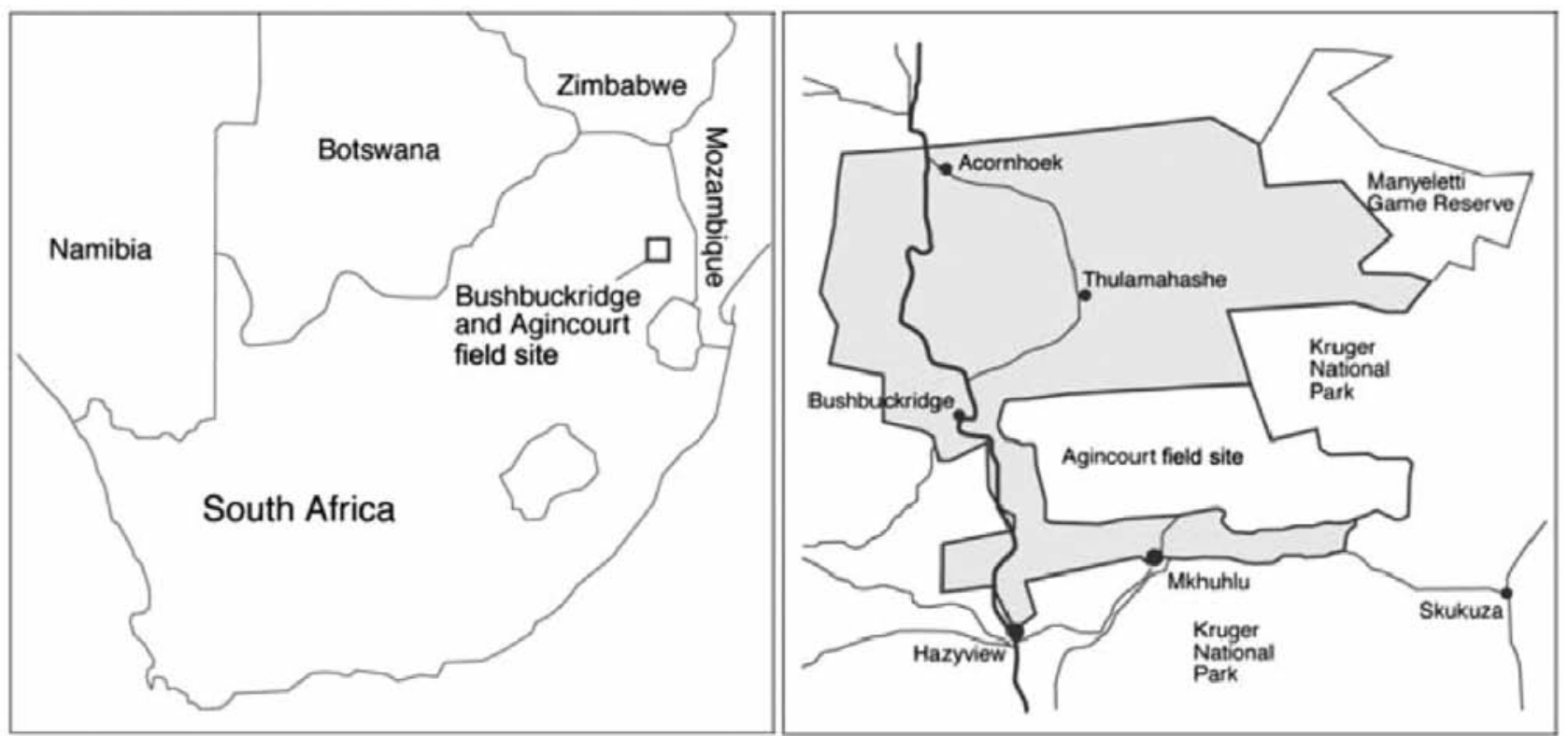

Fig. 1. Location of the Agincourt HDSS site (Kahn et al., 2007), South Africa.

\section{Outcome measures}

A verbal autopsy, validated by Kahn et al. (2000) in the mid-1990s and again in 2005, is conducted for each death within the Agincourt HDSS. Lay, trained fieldworkers interviewed the closest caregiver on the signs and symptoms of the terminal illness, as well as lifestyle risk factors and treatment sought. International Classification of Diseases (ICD-10) was used to classify main, underlying and contributing causes of death following independent assessment of the completed questionnaires by two or three physicians. Where consensus was achieved, the diagnosis was accepted as the 'probable cause of death'; otherwise, the death was classified as 'ill-defined'. Causespecific data (e.g. HIV/AIDS, tuberculosis, acute diarrhoea or malnutrition, acute respiratory infection or pneumonia and accidents) were available from 1992 to 2006 .

\section{Explanatory variables}

The following factors were included as covariates: demographic (gender, nationality), temporal, maternal (nationality, age at pregnancy, death while child aged 1-4 years and education), fertility (parity, birth intervals and sibling death), household mortality experience, socio-economic status (SES), food security, distance to health facility, household elevation (climate proxy) and health seeking behaviour (antenatal clinic attendance). SES is based on information on living conditions and assets, building materials of main dwelling, water and energy supply, ownership of modern appliances and livestock, and means of transport available (Kahn, 2008). The sum of these scores for certain variables provided each household with an overall absolute score. We also used these factors to construct a weighted score using multiple correspondence analysis (MCA). These scores were then divided into five socioeconomic strata ranked by increasing value of the score and corresponding closely to five wealth quintiles: most poor, very poor, poor, less poor and least poor.

\section{Statistical analysis}

The time to death was treated as discrete at monthly intervals and Cox proportional hazards models were fitted using dichotomous logistic regression formulations (D’Agostino et al., 1990). Preliminary regression models were applied to assess the relationship between all-cause child mortality with each covariate. Covariates significant at the $10 \%$ level (without substantial missing values) were then incorporated into a multivariate geostatistical-temporal model to assess the effects of the most significant covariates on child mortality and to develop a predictive model to enable mapping of the mortality outcome. Spatial correlation was modelled via village-specific random effects, which considered as latent observations a spatial Gaussian process. Correlation between any pairs of village locations were considered as an exponential function of their distance and modelled by the covariance matrix of the process (Diggle et al., 1998). Temporal correlation was introduced by yearly random effects modelled 
via an autoregressive process of various order (Schotman, 1994; Zeller, 1996). A Bayesian framework was used to specify the models and Markov chain Monte Carlo (MCMC) simulation was applied to estimate the parameters (Gelfand et al., 1990).

The order of the autoregressive process was assessed using the deviance information criterion (DIC) (Spiegelhalter et al., 2002). Models with the smallest DIC indicate the best fit. Validation was carried out by fitting the models on the subset of data during the period 19922006 and calculating the proportion of villages with observed mortality in 2007 within the 95\% credible intervals of their corresponding predictive distributions.

Autoregressive models of first and second order had similar DICs and similar predictive ability for 2007. However, the second order process converged faster and was thus used in the final model. Further modeling details are given in the Appendix.

Simulation-based Bayesian kriging (Gelfand et al., 1999) at numerous prediction points within the site was used to produce smoothed maps of all-cause and cause- specific mortality risk within the whole Agincourt HDSS. Predictions were carried out at baseline category of the predictors and during the periods of 1992-1995, 1996-1999, 2000-2003 and 20042007. All identifying features (village centroids, boundaries) have been removed from the maps and the prediction area expanded irregularly, in order to ensure confidentiality and avoid stigmatising of villages. The HIV and tuberculosis mortality risk map is also not shown for this reason.

Data extraction and management was done using Microsoft SQL Server 2005. The analysis was carried out in STATA version 10.0 (Stata Corp., 2007), OpenBUGS (Spiegelhalter et al., 1999) and R (R Development Core Team, 2008). The predictions of the fitted spatial models were mapped in Map Info Professional version 9.5 (MapInfo, 2008).

\section{Results}

Between 1992 and 2007, there were 46,675 children aged 1-4 years in the Agincourt HDSS. Each child, on average, contributed 23.67 person months of time (standard deviation (SD) 13.31). There were 565 deaths (6.14 per 1,000 person years) with a mean age at death of 2.20 years (SD 0.93 years). The sex ratio was approximately $1: 1(21,733$ females or $50.3 \%)$ as was the breakdown of children born in the site versus those who in-migrated $(23,423$ or $54.5 \%$ for the former). More than one third $(15,691$ or $36.8 \%)$ of the children were born to former Mozambican refugees.
The top causes of death among children in this period $(\mathrm{n}=535)$ were HIV/tuberculosis $(\mathrm{n}=136,25.4 \%)$, acute diarrhoea or malnutrition $(\mathrm{n}=135,25.2 \%)$, accidents $(\mathrm{n}=31,5.8 \%)$ and acute respiratory infection or pneumonia $(\mathrm{n}=16,3.0 \%)$. In total 314 $(58.7 \%)$ deaths were attributed to infectious or parasitic causes. Fifty-seven deaths $(10.7 \%)$ were classified as unknown (i.e. R95-R99) and 106 deaths (20.3\%) had no diagnosis since a verbal autopsy could not be conducted due to lack of a respondent or family refusal. A significant increasing trend in the child mortality rate was observed over the study period $(\beta=0.05, p=0.001)$. This was observed particularly for the 1992-2003 period (Fig. 2).

Bivariate analyses indicate that winter season, having a Mozambican mother, four or more children aged less than 5 years living in the same household, mother or father death during childhood (1-4 years) especially due to HIV/tuberculosis, father death before birth, increasing number of cumulative household deaths and death of previous sibling are significant factors of child mortality (Table 1). Significant protective factors against child mortality were increasing age of child, increasing mothers age, tertiary level education of mother, increased post-birth interval, mother antenatal clinic attendance as well as increased frequency of antenatal clinic attendance and higher SES quintile of household (Table 1). No significant association was observed between distance from household and nearest health facility. For mothers who died while the child was aged $1-4$ years $(n=259)$, the leading cause of death was HIV/tuberculosis $(30.5 \%)$, while $47.1 \%$ where classified as unknown. This was similar for fathers who died before the child was born or up to the child's $5^{\text {th }}$ birthday $(\mathrm{n}=543,28.7 \%$ HIV/tuberculosis, $33.5 \%$ unknown).

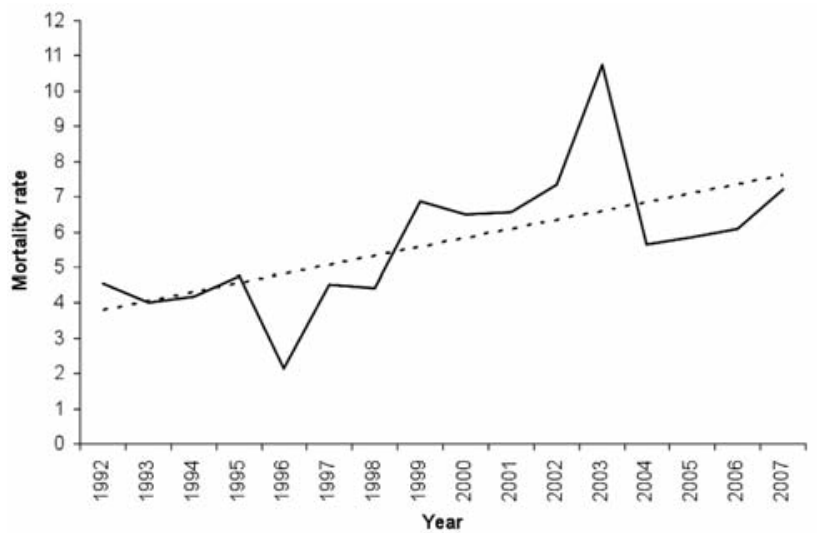

Fig. 2. Child mortality rate per 1,000 person years (with linear trend line) in Agincourt sub-district, 1992-2007. 
Table 1. All-cause bivariate and multivariate child mortality risk factor analyses in Agincourt sub-district, 1992-2007.

\begin{tabular}{|c|c|c|c|}
\hline \multirow[t]{2}{*}{ Factor } & \multicolumn{2}{|c|}{ Bivariate non-spatial model } & \multirow[t]{2}{*}{$\begin{array}{l}\text { Multivariate spatio-temporal } \\
\text { model OR }(95 \% \mathrm{BCI})\end{array}$} \\
\hline & $\mathrm{n}$ & OR $(95 \% \mathrm{CI})$ & \\
\hline \multicolumn{4}{|l|}{ Temporal } \\
\hline By year & $1,136,136$ & $1.05(1.04-1.07)$ & - \\
\hline Winter season & $1,136,136$ & $1.36(1.15-1.60)$ & $1.33(1.12-1.57)$ \\
\hline \multicolumn{4}{|l|}{ Demographic } \\
\hline Age (continuous) & $1,136,136$ & $0.50(0.46-0.55)$ & $0.51(0.46-0.56)$ \\
\hline Male (gender) & $1,135,970$ & $1.07(0.91-1.26)$ & - \\
\hline \multicolumn{4}{|l|}{ Maternal } \\
\hline Mozambican & $13,148 / 35,845$ & $1.72(1.39-2.12)$ & $1.15(0.93-1.40)$ \\
\hline $\begin{array}{l}\text { Mother migration (increasing number of months } \\
\text { spent resident in site in given year of child's life) }\end{array}$ & 665,539 & $0.93(0.89-0.96)$ & (1) \\
\hline \multicolumn{4}{|l|}{$\begin{array}{l}\text { By age (in years) } \\
\text { Bente }\end{array}$} \\
\hline $1-1.99$ & 192,999 & $0.93(0.88-0.98)$ & - \\
\hline $2-2.99$ & 190,637 & $0.90(0.84-0.96)$ & - \\
\hline $3-3.99$ & 194,671 & $1.04(0.89-1.22)$ & - \\
\hline $4-4.99$ & 87,232 & $0.92(0.80-1.06)$ & - \\
\hline Mother death & $1,152 / 1,136,136$ & $5.16(4.03-6.61)$ & - \\
\hline Mother death in 1-4 not due to HIV/tuberculosis & $191 / 1,136,136$ & $7.77(4.43-13.65)$ & $5.17(2.84-8.29)$ \\
\hline Mother death in 1-4 due to HIV/tuberculosis & $66 / 1,136,136$ & $19.92(10.40-38.19)$ & $13.52(7.57-21.68)$ \\
\hline Mother's age & $1,045,197$ & $0.98(0.97-0.99)$ & - \\
\hline Mother's education & 364,244 & $0.98(0.96-1.01)$ & - \\
\hline None & 57,168 & 1.00 & \\
\hline Primary & 96,422 & $1.01(0.69-1.47)$ & - \\
\hline Secondary & 188,891 & $0.94(0.67-1.33)$ & - \\
\hline Tertiary & 21,763 & $0.49(0.23-1.04)$ & - \\
\hline \multicolumn{4}{|l|}{ Paternal } \\
\hline Father death before birth to 4 & $580 / 1,136,136$ & $2.41(1.53-3.82)$ & - \\
\hline Father death before birth to 4 not due to & $430 / 1,136,136$ & $2.07(1.06-4.02)$ & \\
\hline HIV/tuberculosis & & & $1.44(0.73-2.41)$ \\
\hline Father death before birth to 4 due to & $150 / 1,136,136$ & $5.06(2.48-10.41)$ & \\
\hline HIV/tuberculosis & & & $1.99(0.86-3.68)$ \\
\hline \multicolumn{4}{|l|}{ Household demographics } \\
\hline Male household head & 970,917 & $0.78(0.60-1.02)$ & - \\
\hline Mozambican household head & 967,490 & $1.61(1.24-2.09)$ & - \\
\hline Household head age (continuous) & 959,306 & $1.00(0.99-1.01)$ & - \\
\hline $1-3$ children in household aged $<5$ years & $1,008,756$ & 1.00 & 1.00 \\
\hline$\geq 4$ children in household aged $<5$ years & 119,644 & $1.52(1.21-1.91)$ & $1.52(1.18-1.90)$ \\
\hline Household size (count of individuals) & $1,136,132$ & $1.02(1.01-1.04)$ & - \\
\hline Cumulative number of household deaths & $1,136,136$ & & \\
\hline None & 934,491 & 1.00 & \\
\hline 1 & 155,545 & $41.32(30.77-55.49)$ & - \\
\hline $2-3$ & 43,514 & $62.95(45.71-86.71)$ & - \\
\hline$\geq 4$ & 2,586 & $106.90(59.28-192.77)$ & - \\
\hline \multicolumn{4}{|l|}{ Fertility } \\
\hline Pregnancy parity & 23,703 & $0.99(0.90-1.08)$ & - \\
\hline 1 & 14,572 & 1.00 & \\
\hline $2-4$ & 8,560 & $1.05(0.86-1.28)$ & - \\
\hline$\geq 5$ & 571 & $0.20(0.05-0.82)$ & - \\
\hline Preceding birth interval & 7,078 & $0.98(0.95-1.01)$ & - \\
\hline Post birth interval & 6,925 & $0.90(0.82-0.99)$ & - \\
\hline Previous birth stillborn & $288 / 23,703$ & $0.68(0.25-1.84)$ & - \\
\hline Previous sibling died & $800 / 23,703$ & $1.63(1.08-2.45)$ & - \\
\hline Mother attended antenatal clinic & $20,849 / 21,215$ & $0.48(0.28-0.83)$ & - \\
\hline Number of antenatal clinic visits & 14,119 & $0.92(0.88-0.97)$ & - \\
\hline \multicolumn{4}{|l|}{ Socio-economic status (SES) of household } \\
\hline SES MCA ${ }^{\delta}$ score quintiles & 358,524 & & \\
\hline Most poor & 63,390 & 1.00 & \\
\hline Very poor & 69,347 & $0.74(0.51-1.07)$ & - \\
\hline Poor & 73,736 & $0.63(0.43-0.92)$ & - \\
\hline Less poor & 76,396 & $0.60(0.41-0.87)$ & - \\
\hline Least poor & 75,655 & $0.43(0.28-0.66)$ & - \\
\hline Individual variation $\left(\mathrm{O}_{j}^{2}\right)$ & - & 4.1010 .0001 & $0.04(0.01-0.11)$ \\
\hline Spatial variation $\left(\mathrm{O}_{2}^{2}\right)$ & - & - & $0.23(0.10-0.48)$ \\
\hline Temporal variation $\left(\mathrm{O}_{t}^{2}\right)$ & - & - & $0.29(0.12-0.68)$ \\
\hline
\end{tabular}

$\alpha$, Infectious or parasitic child deaths only; $\beta$, no child deaths; $\delta$, similar findings when using the absolute score index; household head age was not significant; straight distance from household and network distance from village centroid to nearest health facility (by category $<5$ and $\geq 5 \mathrm{~km}$ ) were not significant 
We found a strong reduction in the probability of death as the child progresses to the age of 5 years (Fig. 3). This probability is much higher for those children whose mother died of HIV/tuberculosis and remains elevated throughout childhood. For those children whose mother died in childhood due to a cause unrelated to HIV/tuberculosis, we observed an elevated risk between 1-3 years of age, thereafter the risk drops close to levels observed for children whose mother did not die during their childhood.

Results of the multivariate Bayesian spatio-temporal model suggest that mother death between the child's first and fifth birthdays, particularly due to HIV/tuberculosis, was the most prominent risk factor from the multivariate analysis (Table 1), followed by father death due to HIV/tuberculosis, four or more children aged less than 5 years living within the household, Mozambican origin of the mother and winter season. Increasing age remained highly protective. The spatio-temporal model estimated the range or distance at which spatial correlation ceased between villages to be approximately $8.23 \mathrm{~km} \mathrm{(95 \%}$ credible interval: 1.83 to $27.24 \mathrm{~km}$ ). The autoregressive term was between -1 and 1 indicating stationarity.

Distinct foci of higher all-cause mortality risk can be observed (Fig. 4) in the central northern and south-eastern parts of the Agincourt study site. The villages in the southeast of the site are comprised mostly of former Mozambican refugees $(>90 \%$ of village occupants). With increasing distance from the village centroids the standard error of the mortality risk prediction increases.

Child mortality risk due to infectious and/or parasitic causes was higher in the southeast corner of the site towards the Kruger National Park boundary. One additional focus of higher mortality was observed in the central northern part of the site. Distinct foci of reduced child mortality risk due to infectious or parasitic causes were also observed.

HIV/tuberculosis mortality risk showed two distinct foci: one in the upper central part of the site and a grouping in the southeast corner of the site. Acute diarrhoea or malnutrition mortality risk was mostly concentrated in the southeast corner of the site (Fig. 5). A small additional foci was also observed in the upper central part of the site. Mortality risk for acute respiratory infection or pneumonia child deaths was highest in the southeast, upper central and lower southwest of the site (Fig. 5). Accidental mortality risk showed a less distinct pattern however foci of higher mortality risk can be clearly observed across the site (Fig. 5).

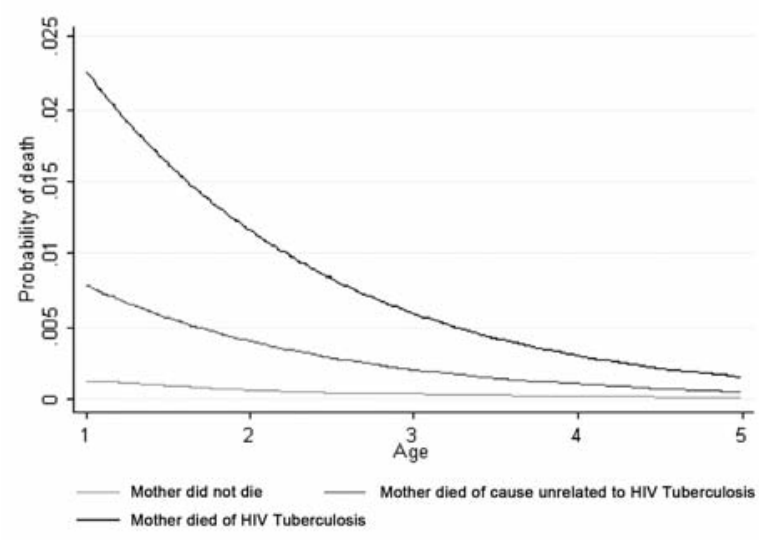

Fig. 3. Probability of death by age during 1-4 years and mother's cause-of-death based on a classical discrete-time logit model which included these two covariates

Fig. 6 shows the distribution of higher risk foci of mortality by period. While the focus of high risk in the southeast corner of the site persists across the period, by 2004 it has spread to surrounding villages. In addition, a new high risk area more upper centrally located emerges in the 2000-2003 period, and intensifies in the next period. Distinct foci of persisting and emerging lower mortality risk are also observed.

\section{Discussion}

In this study Bayesian spatio-temporal models were fitted to assess the geographical patterns and trends of all-cause and cause-specific child mortality in Agincourt HDSS. Results confirmed strong geographic differences in mortality risk and the importance of a number of risk factors such as maternal and paternal death (largely due to HIV), poorer SES and high household mortality burden.

A statistically significant increase in child mortality was observed over the study period, particularly between 1996 and 2003 largely due to the HIV epi-

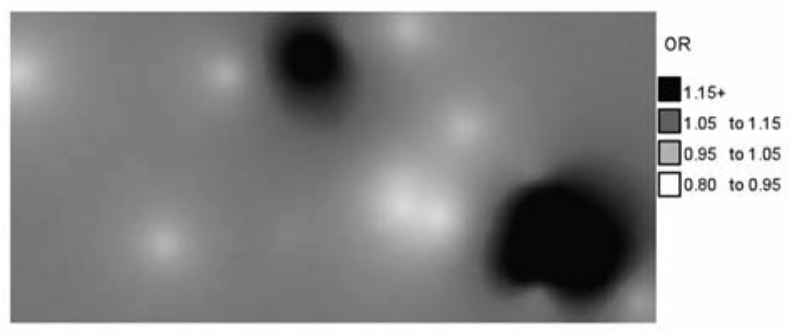

Fig. 4. Smoothed map of all-cause child mortality risk within Agincourt HDSS based on the baseline Bayesian model without covariates. 
Diarrhoea or malnutrition

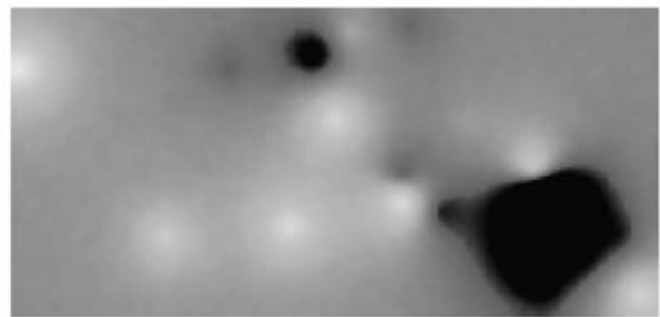

Accidental

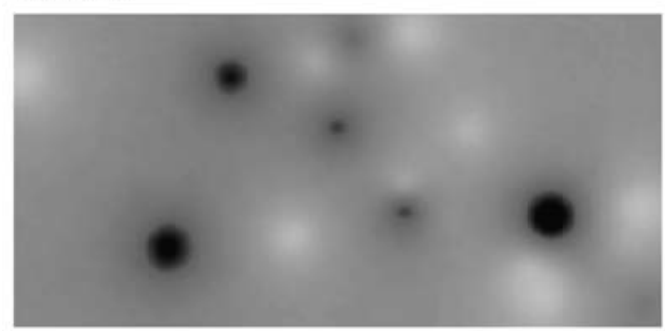

Acute respiratory infection or pneumonia

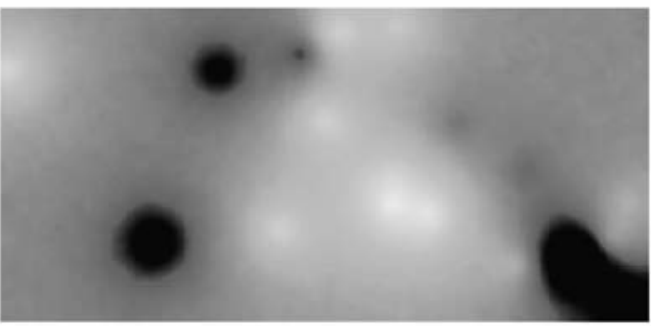

Odds ratio (OR)

$1.10+$

1.05 to 1.09

0.95 to 1.04

0.70 to 0.94

Fig. 5. Smoothed maps of selected cause-specific child mortality risk within Agincourt HDSS based on baseline Bayesian models without covariates.

demic. The leading causes of death were HIV/tuberculosis, followed by diarrhoea/malnutrition. One limitation of this study is the HIV/tuberculosis-related deaths misclassified by the verbal autopsy as unknown, which would underestimate the true burden. Almost half of all child deaths in this area could be attributed to infectious or parasitic causes. Interventions to reduce child mortality targeting infectious causes, specifically HIV and diarrhoea, are therefore urgently needed.

$1992-1995$

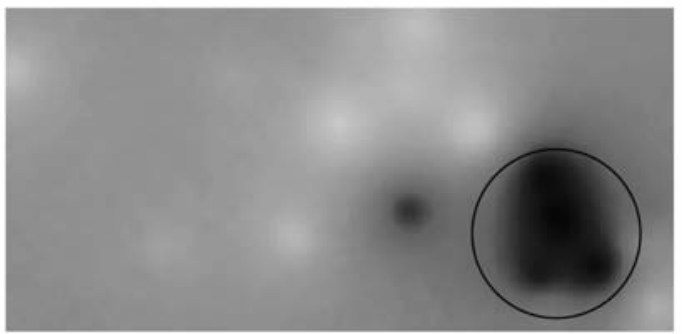

2000-2003

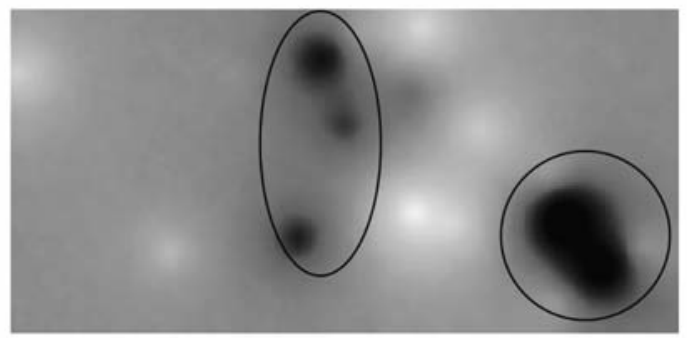

Odds ratio (OR)

$1.20+$
These findings confirm a number of risk factors documented in previous studies (Mosley and Chen, 1984a, b; Hobcraft et al., 1985; Binka et al., 1995; Ronsmans, 1996; Kuate Defo, 1997; Manda, 1999). There was a strong decreasing probability of mortality with increasing age of the child and higher probability of mortality associated with winter season. This is likely due to the increase in respiratory illness during this period, as well as environmental or household pollution due to the burning of fuel (e.g. coal, wood

1996-1999

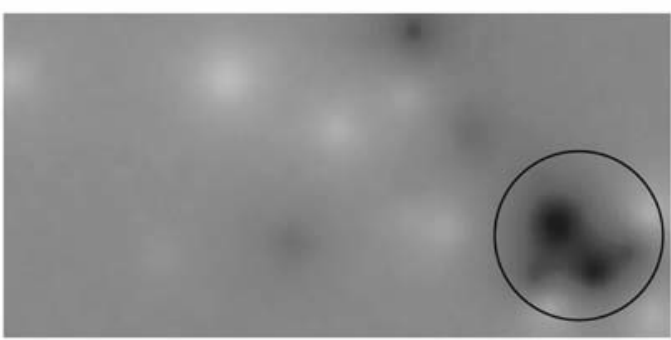

2004-2007

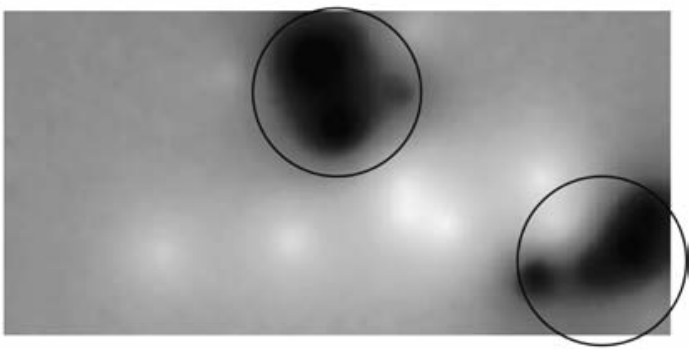

1.05 to 1.09

\subsection{5 to 0.94}

Fig. 6. Smoothed maps of all-cause child mortality risk within Agincourt HDSS by period based on the baseline Bayesian model without covariates. 
and paraffin) for indoor heating and cooking. Results from a previous study in South Africa suggest that exposure to cooking and heating smoke from polluting fuels is significantly associated with $<5$ year mortality (Wichmann et al., 2006).

The spatial analysis indicated two distinct pockets of higher mortality burden towards the southeast and upper central parts of the site. This was consistent with the cause-specific mortality risk distribution we observed for HIV/tuberculosis, diarrhoea/malnutrition and acute respiratory infection/pneumonia. According to the space-time analysis, recent trends indicate the need to target interventions in the southeast corner (high risk throughout the period) and upper central (emerging risk from 2000 onwards) parts of the site which experience the highest mortality burden. This evolving space-time risk distribution is likely being driven by the evolving HIV epidemic.

A strong geographical pattern with regards to higher infectious disease mortality risk (particularly HIV/tuberculosis and diarrhoea) in the former Mozambican settlements lying to the east of the site was observed. We also found a significant risk for allcause child mortality associated with having parents of Mozambican origin. Many refugees fleeing the civil war in Mozambique from 1983 onwards settled in the northeast of South Africa, including in Mpumalanga province. Despite voluntary repatriation programmes following a formal peace agreement in 1992, it was estimated that by 2000 more than 200,000 former Mozambican refugees were still living in the province (Johnston, 2000). They have remained a poorer and more vulnerable group, living in isolated villages with less or weaker in frastructure, poor access to water and sanitation, generally further away from health facilities and labour markets, with limited legal rights and experience barriers to accessing social grants, education and health services (Dolan et al., 1997, Hargreaves et al., 2004; Kahn, 2008). Hargreaves and colleagues (2004) have demonstrated higher mortality rates among children from Mozambican-headed households when compared to South African-headed households; lack of legal status and poorer SES of many former Mozambican refugees partly explains this disparity. Although primary health care is free, transport costs are high which represents a problem as the Mozambican settlements are generally further away from health services. Lack of legal status means Mozambican children do not have the same access to child support grants, which puts them at a further disadvantage relative to their South African counterparts. Hence, despite equity-orientated health and social policies in the southern part of the study site, it would appear that generally those children who are hardest to reach, both physically and socially, are also those with the highest mortality. Policy amendments are therefore needed to address inequity and any differential access to various services.

Death of the child's mother (and father to a smaller extent) between their first and fifth birthdays (specifically due to HIV/tuberculosis) was the most prominent risk factor in this study. Vertical transmission of HIV and/or loss of the primary care giver (leading to a loss of direct care as well as indirectly through household income lost) are the most likely explanation for this finding. Access to voluntary counselling and testing and anti-retroviral treatment to mothers and fathers in these settlements needs to be increased. About half of children infected with HIV through vertical transmission develop AIDS symptoms and die within 2 years (UNAIDS, 2002). Fig. 3 illustrates this issue. A comprehensive approach to prevention of mother-to-child transmission (PMTCT), including a combination of antiretroviral therapy (ART) from early pregnancy, elective caesarean section and highly active anti-retroviral therapy (HAART) for mother or infants during breastfeeding (Coovadia et al., 2007; WHO, 2010), can significantly reduce transmission rates in this sub-district (European Collaborative Study, 2005; Navér et al., 2006; Newell et al., 2007). In resource-poor settings, the risks and costs of surgical procedures are barriers to considering caesarean sections as a feasible strategy for preventing MTCT. The avoidance of breastfeeding in absence of HAART must also be balanced against the risks associated with replacement feeding such as cost and lack of access to clean water (Thior et al., 2006; Coovadia et al., 2007) which we have shown to be a problem in the south east region of the site.

The strong clustering of diarrhoea/malnutritionrelated mortality risk in the southeast corner of the site, again in former Mozambican refugee settlements, points to a deficiency in water and/or sanitation infrastructure, which needs to be further assessed and addressed by local government. We recommend routine testing and improved water supply to reduce these unnecessary deaths. Rehydration fluid (ORT) and dietary management are key aspects in the treatment of acute diarrhoea, particularly those episodes which persist. The capabilities and resources of health facilities, specifically those situated near to the southeast corner of the site, to effectively manage children presenting with diarrhoea and/or malnutrition needs to be improved. 
The association between SES, maternal education and mortality has been previously described by Farah and Preston (1982). Higher education may result in better health awareness and utilisation of health facilities (Jain, 1988), higher income and the ability to purchase goods and services that improve children's health (Schultz, 1979), longer birth intervals and, possibly, higher maternal ages (Cleland et al., 1989).

Death of household members other than the mother or father also appeared to be a significant risk in this study. Thus death of these members places additional strain (including financial burden of medical services and funerals, and loss of income) on the household, which negatively impacts on the child's health outcome. High mortality households require both financial and social support to reduce the indirect impact on their children.

There are several studies relating geographical access to use of health facilities. As one would expect, members of communities that are more distant use the facilities less than those that live nearer, but this does not necessarily translate into increased mortality risk (Stock, 1983; Becher et al., 2008). In this study no significant increased risk of child mortality was found with increasing distance of household to the nearest primary health care clinic as well as district hospitals located outside the site. The same holds true for infant mortality (Sartorius et al., 2010). This suggests that quality of health services may be influencing child mortality rather than geographical access. Evaluation of primary health care services with attention to quality improvements is needed.

\section{Conclusion}

Our study has demonstrated the considerable potential of spatial statistical methods for analysing longitudinal health and socio-demographic data, and is one of only a few studies to have used geostatistical modelling on HDSS mortality data. Based on the spacetime analysis the southeast and upper central regions of the site appear to have the highest child mortality risk at present. These maps are particularly helpful in identifying high mortality areas to guide efficient allocation of limited resources in child survival programmes. The risk factor results can also contribute to policies to address health inequalities in rural South Africa and to improve access to health services. Targeted efforts to prevent vertical transmission of HIV in specific villages need to be introduced, as well as programmes to ensure the survival of the mother and father through children's childhood, as both emerged as prominent risk factors for child mortality.

\section{Acknowledgements}

This work was supported by a PhD fellowship from the South African Centre for Epidemiological Modeling and Analysis (SACEMA), a National Research Foundation (NRF) Centre of Excellence, as well as research fellowships from the MRC/Wits Rural Public Health and Health Transitions Research Unit (Agincourt) through the Wellcome Trust (grant no. 069683/Z/02/Z), UK, and the Swiss-South Africa Joint Research Programme (project no. JRP IZLSZ3_122926). Additional funding was provided by a Wits Faculty of Health Sciences Medical Research Endowment Fund (MREF) (grant no. SARB000) and a research fellowship from the MRC/Wits Rural Public Health and Health Transitions Research Unit (Agincourt) through the Wellcome Trust, UK. The Agincourt HDSS and GIS was funded by the Wellcome Trust, UK (grant no. 058893/Z/99/A, 069683/Z/02/Z, 069683/Z/08/Z), the University of the Witwatersrand, the South African Medical Research Council, and the Andrew W. Mellon Foundation, USA. P. Vounatsou was supported by the Swiss National Science Foundation (project no. 325200_118379).

\section{Appendix: Statistical model}

Let $Y_{i j t}$ be the mortality status of child $i$ in village $j$ at time interval $t$. We assume that $Y_{i j t}$ arises from a Bernoulli distribution, $Y_{i j t} \sim \operatorname{Be}\left(p_{i j t}\right)$ where $p_{i t}$ is the probability of death of child $i$ at interval $t$. We model covariates $X_{i t}$, temporal random effect $\alpha_{t}$, village $\varphi_{t}$ and child $\varepsilon_{t}$ random effects on the logit of $p_{i j t}$, that is $\log i t\left(p_{i j t}\right)=X_{i t}^{T}+\beta+\alpha_{t}+\varphi_{j}+\varepsilon_{i}$, where $\beta$ is the vector of regression coefficients. We assume that $\varphi_{i}$ has a multivariate normal distribution, $\varphi \sim \operatorname{MVN}(0, \Sigma)$ with variance-covariance matrix $\Sigma$. We also assume an isotropic stationary spatial process, where $\Sigma_{k l} \sim \sigma_{\varphi}^{2} \exp \left(-\rho d_{k l}\right), d_{k l}$ is the Euclidean distance between villages $k$ and $l, \sigma_{\varphi}^{2}$ is the geographical variability known as the sill, $\rho$ is a smoothing parameter that controls the rate of correlation decay with increasing distance and measures the range of geographical dependency (Diggle et al.., 1998). The range is defined as the minimum distance at which spatial correlation between locations is below $5 \%$. This distance can be calculated as $3 / \rho$ and is expressed in meters. The year level temporal random effect $\alpha_{t} t=1,2, \ldots, 16$, was modelled via a second order stationary autoregressive process that is $\alpha_{t} \sim N\left(\gamma_{1} \alpha_{t-1}\right.$ $\left.+\gamma_{2} \alpha_{t-2}, \sigma_{\varphi}^{2}\right), t>2$, where $-2<\gamma_{1}<2$ and $-1<\gamma_{2}<1-\left|\gamma_{1}\right|$ (Harvey, 1993) and the child random effects via independent normal distributions $\varepsilon_{i} \sim N\left(0, \sigma_{z}^{2}\right)$ with variance $\sigma_{z}^{2}$. Uniform prior distributions were adopted for $\gamma_{1}, \gamma_{2}$, vague Normal distributions for the $\beta$, inverse gamma priors for the variance parameters and a uniform prior for $\rho$. The model was fitted using MCMC in OpenBUGS. A burn in of 5,000 was chosen 
and run until the Monte Carlo error was $<5 \%$ SD for each covariate, thereafter run until sample of 10,000 obtained.

\section{References}

Adetunji J, 2000. Trends in under-5 mortality rates and the HIV/AIDS epidemic. Bull World Health Organ 78, 12001206.

Ahmad OB, Lopez AD, Inoue M, 2000. The decline in child mortality: a reappraisal. Bull World Health Organ 78, 1175 1191.

Becher H, Kynast-Wolf G, Sie A, Ndugwa R, Ramroth H, Kouyate B, Müller O, 2008. Patterns of malaria: cause-specific and all-cause mortality in a malaria-endemic area of West Africa. Am J Trop Med Hyg 78, 106-113.

Binka FN, Maude GH, Gyapong M, Ross DA, Smith PG, 1995. Risk factors for child mortality in northern Ghana: a case-control study. Int J Epidemiol 24, 127-135.

Black RE, Morris SS, Bryce J, 2003. Where and why are 10 million children dying every year? Lancet 361, 2226-2234.

Cleland J, van Ginneken JK, 1989. Maternal education and child survival in developing countries: the search for pathways of influence. Soc Sci Med 27, 1357-1368.

Clements ACA, Garba A, Sacko M, Touré S, Dembelé R, Landouré A, Bosque-Oliva E, Gabrielli AF, Fenwick A, 2008. Mapping the probability of schistosomiasis and associated uncertainty, West Africa. Emerg Infect Dis 14, 1629-1632.

Coovadia H, Bland R, 2007. Preserving breastfeeding practice through the HIV pandemic. Trop Med Int Health 12, 1-18.

Coovadia H, Rollins N, Bland M, Little K, Coutsoudis A, Bennish M, Newell ML, 2007. Mother-to-child transmission of HIV-1 infection during exclusive breastfeeding in the first 6 months of life: an intervention cohort study. Lancet 369 , 1107-1116.

D'Agostino R, Lee M, Belanger A, 1990. Relation of pooled logistic regression to time dependent Cox regression analysis: The Framingham Heart Study. Stat Med 9, 1501-1515.

Diggle P, Tawn J, Moyeed R, 1998. Model-based geostatistics. Appl Stat 47, 299-350.

Dolan C, Tollman S, Nkuna V, Gear J, 1997. The links between legal status and environmental health: a case study of Mozambican refugees and their hosts in the Mpumalanga (Eastern Transvaal) Lowveld, South Africa. Int Health Hum Rights 2, 62-84.

European Collaborative Study, 2005. Mother-to-child transmission of HIV infection in the era of highly active antiretroviral therapy. Clin Infect Dis 40, 458-465.

Farah AA, Preston SH, 1982. Child mortality differentials in Sudan. Popul Dev Rev 8, 365-383.

Gelfand A, Ravishanker N, Ecker M, 1999. Modelling and inference for point-referenced binary spatial data. In: Generalized Linear Models: A Bayesian Perspective, Dey D,
Ghosh S, Mallick B, eds. Marcel Dekker Inc. 373-386.

Gelfand A, Smith A, 1990. Sampling-based approaches to calculating marginal densities. J Am Stat Assoc 85, 398-409.

Gemperli A, Vounatsou P, Sogoba N, Smith T, 2006. Malaria mapping using transmission models: application to survey data from Mali. Am J Epidemiol 163, 289-297.

Gosoniu L, Vounatsou P, Tami A, Nathan R, Grundmann H, Lengeler C, 2008. Spatial effects of mosquito bednets on child mortality. BMC Public Health 8, 356.

Hargreaves J, Collinson M, Kahn K, Clark S, Tollman S, 2004. Childhood mortality among former Mozambican refugees and their hosts in rural South Africa. Int J Epidemiol 33, 1271-1278. Hay S, Guerra CA, Gething PW, Patil AP, Tatem AJ, Noor AM, Kabaria CW, Manh BH, Elyazar IRF, Brooker S, Smith DL, Moyeed RA, Snow RW, 2009. A world malaria map: Plasmodium falciparum endemicity in 2007. PLoS Med 6, e1000048.

Hobcraft JN, McDonald JW, Rutstein SO, 1985. Demographic determinants of infant and early child mortality: a comparative analysis. Population Stud 39, 363-385.

Jain A, 1988. Determinants of regional variation in infant mortality in rural India. In: Infant Mortality in India: Differentials and Determinants, Jain A, Visaria L, eds. Sage Publications, 127-167.

Johnston N, 2000. The Regularisation of Former Mozambican Refugees in South Africa: Experiences and Lessons. Acornhoek, Refugee Research Programme.

Kahn K, 2008. Dying to make a fresh start: mortality and health transition in a new South Africa. Umeå University Medical Dissertations New Series No. 1056, ISSN 0346-6612 ISBN 91-7264-173-8.

Kahn K, Tollman SM, Collinson MA, Clark SJ, Twine R, Clark BD, Shabangu M, Gómez-Olivé FX, Mokoena O, Garenne ML, 2007. Research into health, population and social transitions in rural South Africa: data and methods of the Agincourt health and demographic surveillance system. Scand J Public Health 35 (Suppl 69), 8-20.

Kahn K, Tollman SM, Garenne M, Gear JS, 2000. Validation and application of verbal autopsies in a rural area of South Africa. Trop Med Int Health 5, 824-831.

Kuate Defo B, 1997. Effects of infant feeding practices and birth spacing on infant and child survival: a reassessment from retrospective and prospective data. J Biosoc Sci 29, 303-326.

Manda S, 1999. Birth intervals, breastfeeding and determinants of childhood mortality in Malawi. Soc Sci Med 48, 301-312.

MapInfo, 2008. MapInfo Professional. Version 9.5. Pitney Bowes Software Inc., One Global View, Troy, New York.

Mosley WH, Chen LC, 1984a. An analytical framework for the study of child survival in developing countries. In: Child Survival: Strategies for Research, Mosley WG, Chen LC, eds, New York: Population Council, 25-44.

Mosley WH, Chen LC, 1984b. An analytic framework for the 
study of child survival in developing countries. Popul Dev Rev 10, 25-45

Mulholland E, Smith L, Carneiro I, Becherc H, Lehmannd D, 2008. Equity and child-survival strategies. Bull World Health Organ 86, 399-407.

Müller O, Garenne M, 1999. Childhood mortality in subSaharan Africa. Lancet 353, 673.

Navér L, Lindgren S, Belfrage E, Gyllensten K, Lidman K, Gisslén M, Ehrnst A, Arneborn M, Bohlin AB, 2006. Children born to HIV-1-infected women in Sweden in 1982-2003: trends in epidemiology and vertical transmission. J Acquir Immune Defic Syndr 42, 484-489.

Newell ML, Huang S, Fiore S, Thorne C, Mandelbrot L, Sullivan JL, Maupin R, Delke I, Watts DH, Gelber RD, Cunningham CK, PACTG 316 Study Team, 2007. Characteristics and management of HIV-1-infected pregnant women enrolled in a randomised trial: differences between Europe and the USA. BMC Infect Dis 7, 60.

Penchansky R, Thomas J, 1981. The concept of access - definition and relationship to consumer satisfaction. Med Care 19, 127-140.

R Development Core Team, 2008. R: a language and environment for statistical computing. R Foundation for Statistical Computing, Vienna, Austria. ISBN 3-900051-07-0, URL http://www.R-project.org.

Raso G, Matthys B, N'Goran EK, Tanner M, Vounatsou P, Utzinger J, 2005. Spatial risk mapping and prediction of Schistosoma mansoni infections among schoolchildren living in western Côte d'Ivoire. Parasitology 131, 97-108.

Riedel N, Vounatsou P, Miller J, Gosoniu L Chizema-Kawesha E, Mukonka V, Steketee RW, 2010. Geographical patterns and predictors of malaria risk in Zambia: Bayesian geostatistical modelling of the 2006 Zambia national malaria indicator survey (ZMIS). Malar J 9, 37.

Ronsmans C, 1996. Birth spacing and child survival in rural Senegal. Int J Epidemiol 25, 989-997.

Sartorius BKD, Kahn K, Vounatsou P, Collinson MA, Tollman SM, 2010. Young and vulnerable: spatial-temporal trends and risk factors for infant mortality in rural South Africa (Agincourt), 1992-2007. BMC Public Health 10, 645.

Schotman P, 1994. Priors for the AR (1) model: parameterization issues and time series considerations. Economet Theor 10, 579-595.

Schultz TP, 1979. Interpretation of relations among mortality, economics of the household and the health environment. In: Proceedings of the Meeting on Socio-Economic Determinants and Consequences of Mortality Mexico City, June 19-25 Geneva: World Health Organization.

Schur N, Hürlimann E, Garba A, Traoré MS, Ndir O, Ratard RC, Tchuem Tchuenté LA, Kristensen TK, Utzinger J,
Vounatsou P. 2011. Geostatistical model-based estimates of schistosomiasis prevalence among individuals $\leq 20$ years in West Africa. PLoS Negl Trop Dis (in press).

Spiegelhalter D, Best N, Carlin B, van der Linde A, 2002. Bayesian measures of model complexity and fit. J R Stat Soc B 64, 583-639.

Spiegelhalter D, Thomas A, Best N, 1999. WinBUGS Version 1.2 User Manual MRC Biostatistics Unit.

StataCorp, 2007. Stata Statistical Software: Release 10. College Station, TX: StataCorp. LP.

Stock R, 1983. Distance and the utilization of health facilities in rural Nigeria. Soc Sci Med 17, 563-570.

Thior I, Lockman S, Smeaton LM, Shapiro RL, Wester C, Heymann SJ, Gilbert PB, Stevens L, Peter T, Kim S, van Widenfelt E, Moffat C, Ndase P, Arimi P, Kebaabetswe P, Mazonde P, Makhema J, McIntosh K, Novitsky V, Lee TH, Marlink R, Lagakos S, Essex M; Mashi Study Team, 2006. Breastfeeding plus infant zidovudine prophylaxis for 6 months vs formula feeding plus infant zidovudine for 1 month to reduce mother-to-child transmission in Botswana. JAMA 296, 794-805. Tollman SM, Herbst K, Garenne M, Gear JS, Kahn K, 1999. The Agincourt demographic and health study-site description, baseline findings and implications. S Afr Med J 89, 858-864.

Trapé JF, 2001. The public health impact of chloroquine resistance in Africa. Am J Trop Med Hyg 64 (Supp), 12-17.

Tulloch J, 1999. Integrated approach to child health in developing countries. Lancet 354 (Suppl 2), 16-20.

UNAIDS, 2002. Paediatric HIV infection and AIDS: UNAIDS point of view. (UNAIDS best practice collection. Point of view.) Geneva: UNAIDS.

Victora CG, Wagstaff A, Schellenberg JA, Gwatkin D, Claeson M, Habicht JP, 2003. Applying an equity lens to child health and mortality: more of the same is not enough. Lancet 362, 233-241.

Wagstaff A, 2000. Socioeconomic inequalities in child mortality: comparisons across nine developing countries. Bull World Health Organ 78, 19-29.

WHO, 2002. The world health report 2002: reducing risks, promoting healthy life. Geneva: World Health Organization.

WHO, 2010. Guidelines on HIV and infant feeding. Principles and recommendations for infant feeding in the context of HIV and a summary of evidence. Geneva: World Health Organization. http://www.who.int/child_adolescent_health/ documents/9789241599535/en/index.html (accessed 4 September 2010).

Wichmann J, Voyi K, 2006. Influence of cooking and heating fuel use on 1-59 month old mortality in South Africa. Matern Child Health J 10, 553-561.

Zeller A, 1996. An Introduction to Bayesian Inference and Econometrics. John Wiley and Sons Ltd/Inc: New York. 